\title{
Modelling of Two-Way Bellow Actuator Positioning
}

\author{
Pavel Chernus, Valery Sharovatov, Petr Chernus \\ Baltic State Technical University «VOENMEH» named after D.F.Ustinov, 1-st Krasnoarmeyskaya 1, 190005, \\ Saint-Petersburg, Russia
}

\begin{abstract}
This paper deals with position simulation of two-way bellow actuator consisting of two bellow actuators in antagonistic connection based on bellow actuators produced by Festo. The main point of paper is design and simulation of the mathematical model with emphasis on consideration of transfer function parameters variation during two-way bellow actuator performance. The model was created and simulated in Matlab's Simulink environment.
\end{abstract}

Keywords: bellow actuator; modelling; positioning; antoganistic configuration; parameters variation
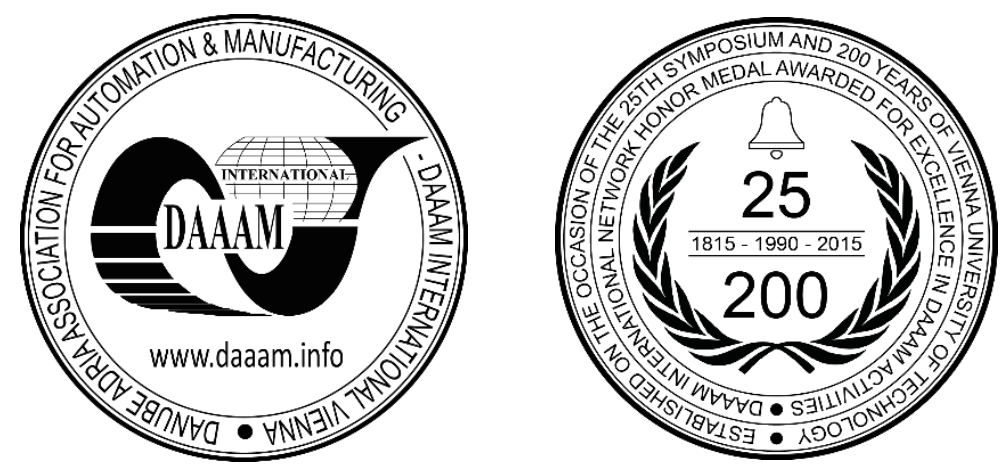

This Publication has to be referred as: Chernus, P[avel]; Sharovatov, V[alery] \& Chernus, P[etr] (2016). Modelling of Two-Way Bellow Actuator Positioning, Proceedings of the 26th DAAAM International Symposium, pp.0620-0625, B. Katalinic (Ed.), Published by DAAAM International, ISBN 978-3-902734-07-5, ISSN 1726-9679, Vienna, Austria DOI: $10.2507 / 26$ th.daaam.proceedings.084 


\section{Introduction}

Recently interest for pneumatic membranate elements of different types has grown up. It confirms increased number of publications, where are made some researches of such elements [1,2,3]. Mainly is investigated pneumatic air muscle (PAM), which belong to the pull-type element. Researches of modelling of some actuators based on PAMs become more needed $[4,5]$.

In this paper will be considered more detailed push-type membranate elements. Bellow actuators (BA), produced by Festo, refer to one-way push-type pneumatic membranate elements (Fig. 1). It can replace classic pneumatic cylinder. As far as two-way pneumatic cylinder is mostly applied for different actuators, was designed a mathematical model of two-way bellow actuator [6], consisting of two bellow actuators in antagonistic connection (Fig. 2). In the process resultant position of movable plate $\mathrm{h}$ depends on tensile forces produced by bellow actuators $\left(\mathrm{F}_{1}, \mathrm{~F}_{2}\right)$, according to different pressures inside bellow actuators $\left(\mathrm{p}_{1}, \mathrm{p}_{2}\right)$. Neutral position of the movable plate can be achieved with equilibrium of pressures inside bellow actuators. The pressures in bellow actuators are controlled by four ON/OFF solenoid valves: two for BA filling (inlet solenoid valves $\mathrm{SV}_{-} \mathrm{i}_{1}$ and $\mathrm{SV} \mathrm{i}_{2}$ ) and two for emptying (outlet solenoid valves $\mathrm{SV}_{-} \mathrm{o}_{1}$ and $\left.\mathrm{SV} \_\mathrm{O}_{2}\right)$.

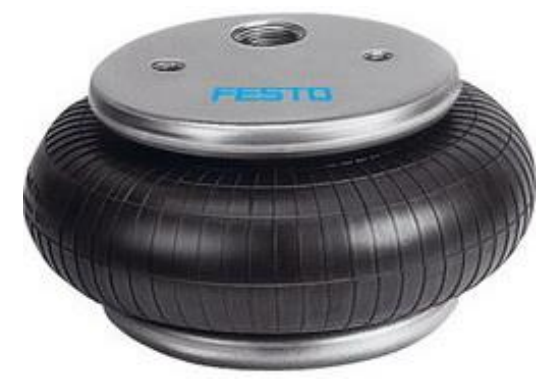

Fig. 1. Bellow actuator design

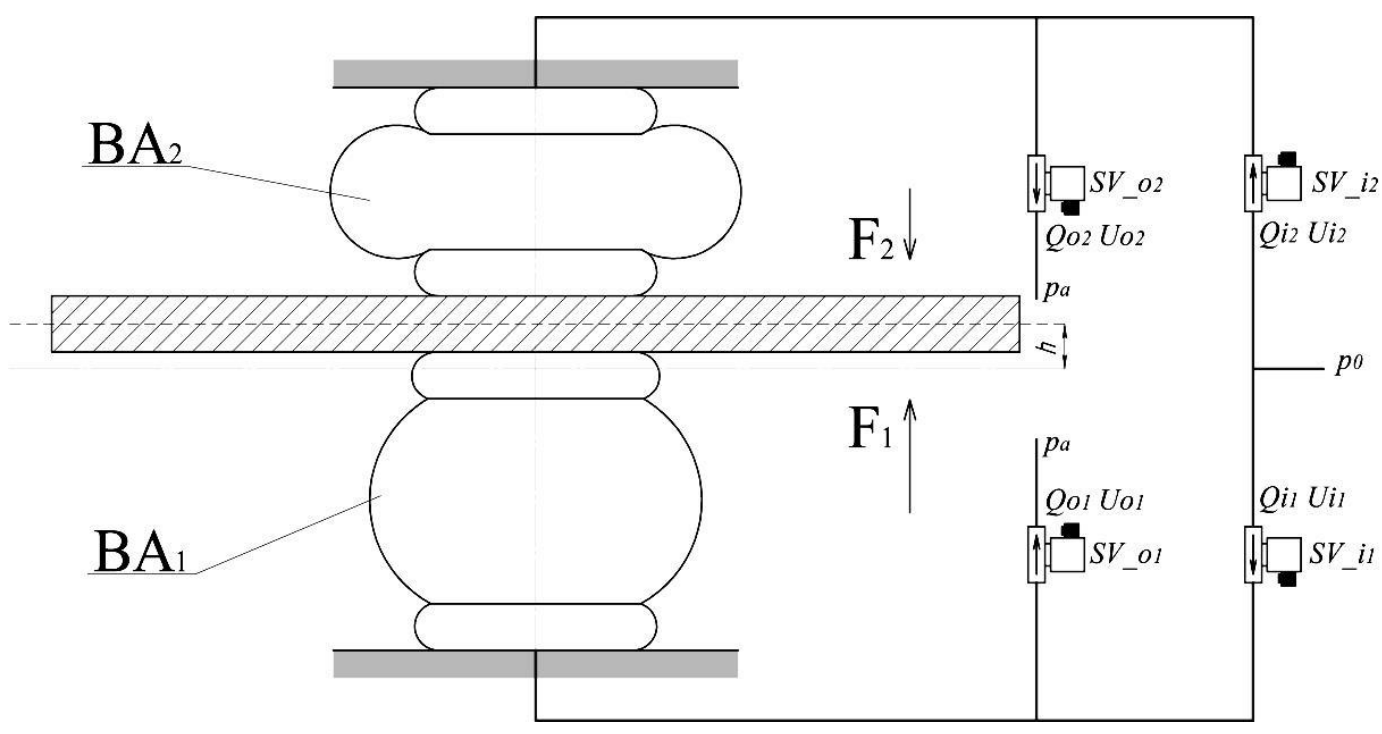

Fig. 2. Position actuator of two-way bellow actuator

\section{Simulation model of two-way bellow actuator}

Here is shown a simulation model of two-way bellow actuator created by authors in Matlab's Simulink environment (Fig. 3). Developed model is based on mathematical model of two-way bellow actuator, which consider gas dynamics processes inside bellow actuator.

Bellow actuator load force assumes constant value. Index number 1 pass for the first bellow actuator - BA1 and index number 2 for the second bellow actuator - BA2, subscript $i$ pass for inflation of the BA and subscript o for deflation of the BA.

By opening (control voltage $U i$ ) of the appropriate inlet solenoid valve the air flow rate $Q i$ will be on its output after some time delay. Pressure inside bellow actuator will increase according to pressure difference between input and output inlet solenoid valve. In this case longitudinal dimension of bellow actuator increases.

By opening (control voltage $U o$ ) of the appropriate outlet solenoid valve compressed air will deflate from muscle (air flow rate $Q o$ ) and reduction of its longitudinal dimension. 
The resultant position of movement plate is specified by load force and tensile forces produced by bellow actuators (BA1, BA2).

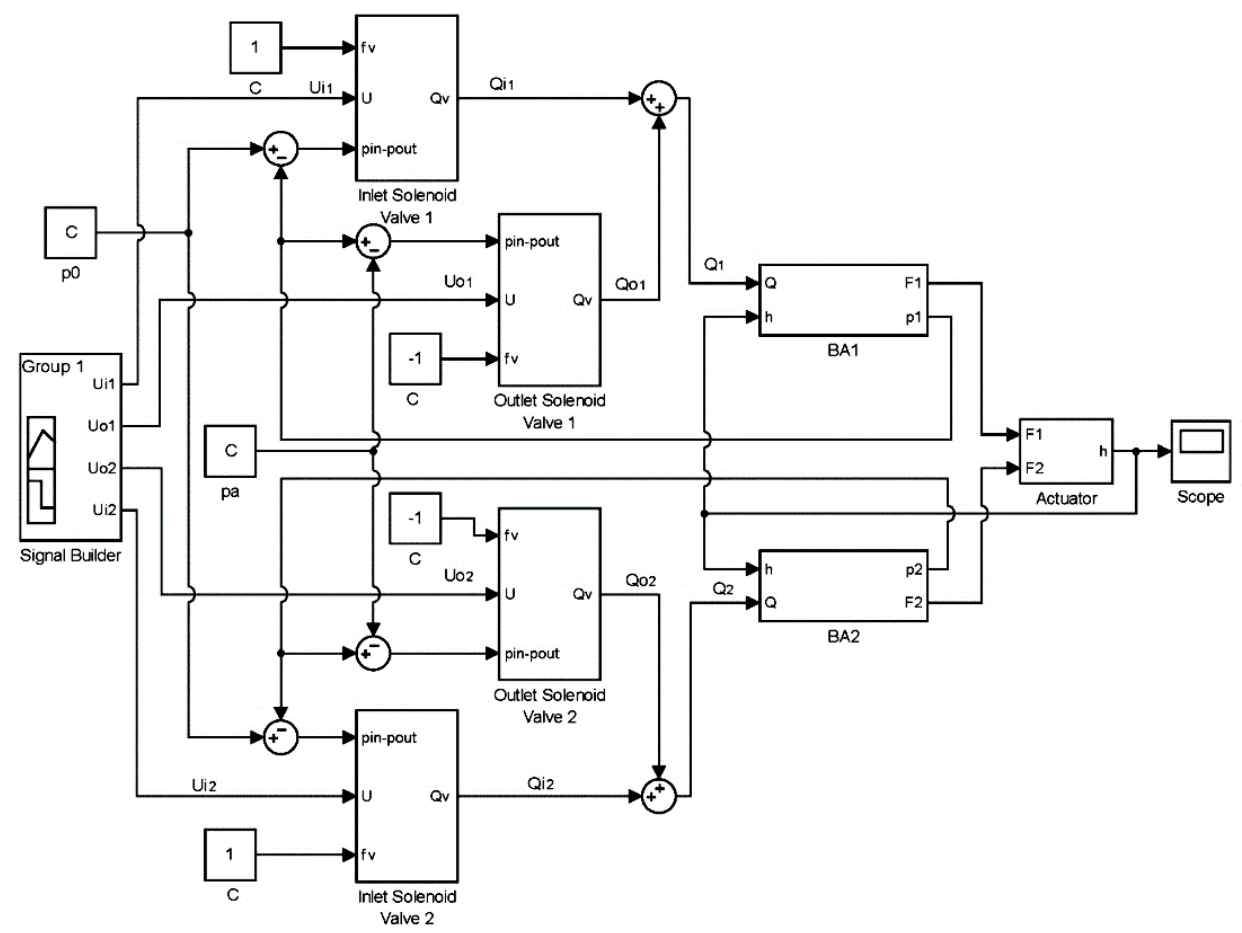

Fig. 3. Simulation model of two-way bellow actuator

\section{Nonlinearities of two-way bellow actuator mathematical model}

Modelling in Matlab's Simulink environment is based on mathematical model of one-way bellow actuator. Development of this model is shown in the paper [7]. This mathematical model is nonlinear. During its development were found necessary static characteristics. Let's study main of them.

\subsection{Nonlinearity of load bearing characteristics}

Load bearing characteristics are shown in Festo catalogue [8] (Fig. 4a). They show connection between force, produced by bellow actuator $\mathrm{F}_{\mathrm{BA}}$, and its current height. On Fig. $4 \mathrm{~b}$ are shown similar characteristics build by equation (1) [7]. Calculations were made for bellow actuator EB-145-60.

\section{EB-145-60}

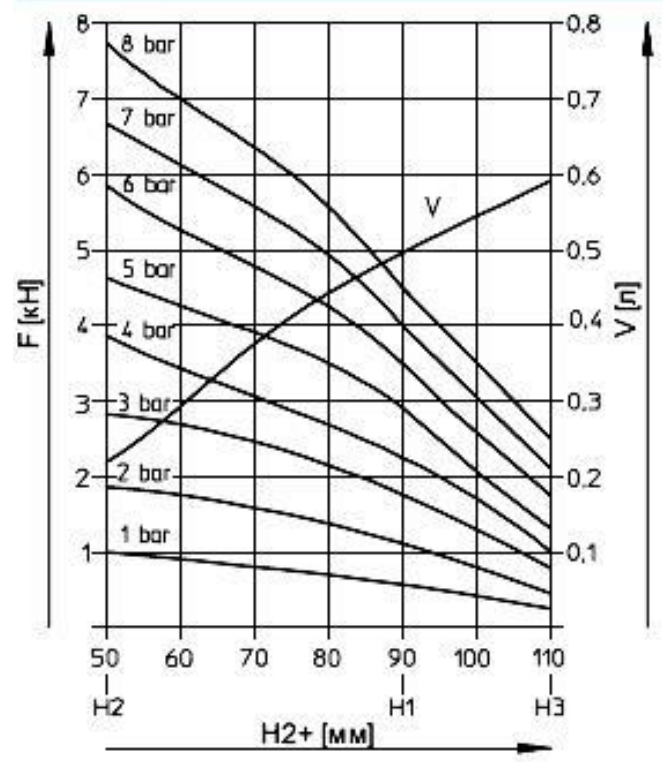

a)

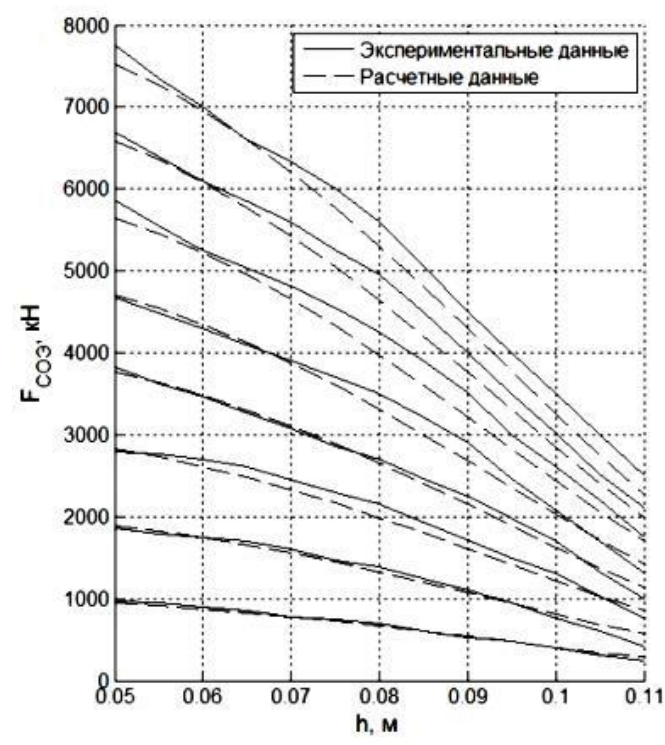

b)

Fig. 4. Load bearing characteristics 


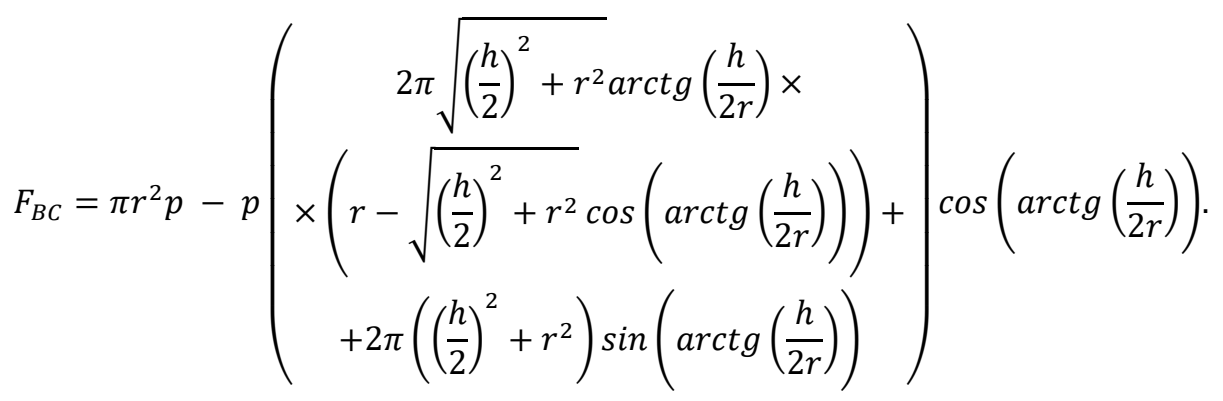

\subsection{Bellow actuator volume nonlinearity}

This characteristic also is shown in Festo catalogue (Fig. 5a). It describes connection between volume of bellow actuator $\mathrm{V}_{\mathrm{BA}}$ and its current height. Mathematical interpretation of this dependence can be calculated with a help of equation (2) [7]. Plot log of it is shown at Fig. 5b.

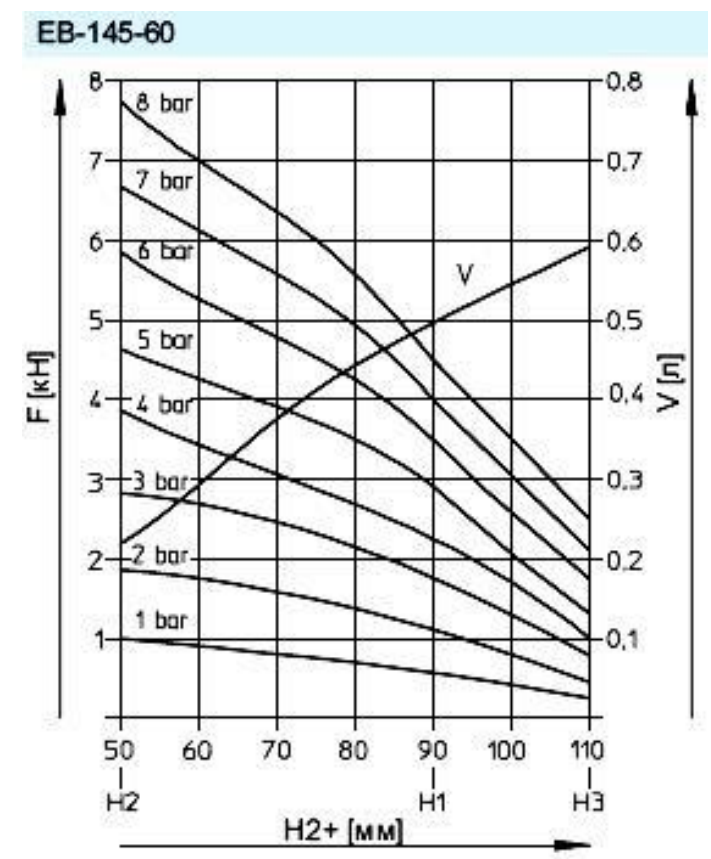

a)

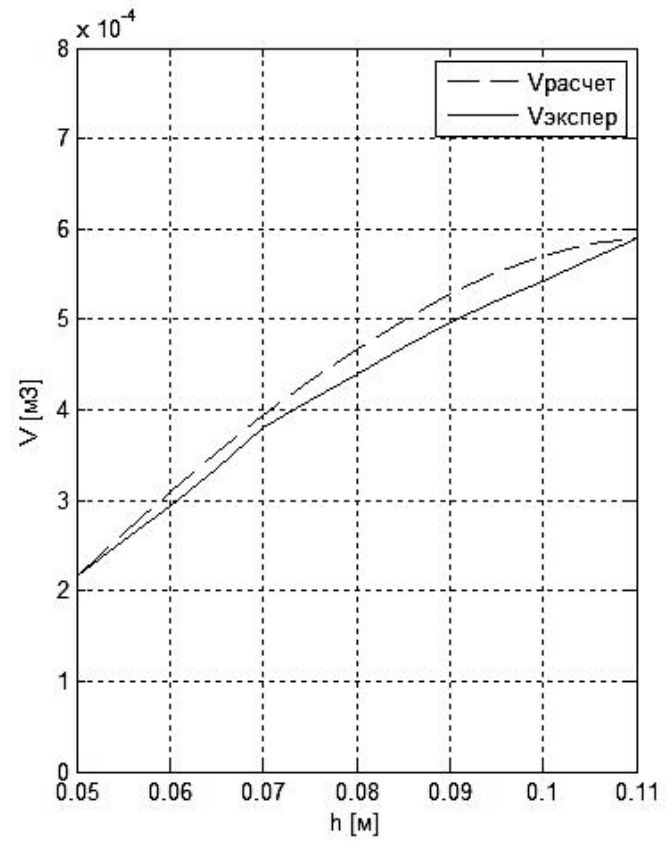

b)

Fig. 5. Bellow actuator volume characteristic

$$
V_{B A}=\pi r^{2} h+2 \pi r \cdot\left(\begin{array}{c}
\operatorname{arctg}\left(\frac{h}{2 r}\right)\left(\left(\frac{h}{2}\right)^{2}+r^{2}\right)- \\
-\frac{1}{2}\left(\left(\frac{h}{2}\right)^{2}+r^{2}\right) \sin \left(2 \operatorname{arctg}\left(\frac{h}{2 r}\right)\right)
\end{array}\right)
$$

\subsection{Nonlinearity of coefficient of correlation between height increment and pressure increment}

This characteristic is necessary for development of mathematical model of bellow actuator. And it is not represented in Festo catalogue. It can be obtained only when load force is constant (e.g. load mass, friction, etc.). This characteristic can be calculated by equation (3) [9]. It's plot log is shown at Fig. 6. 


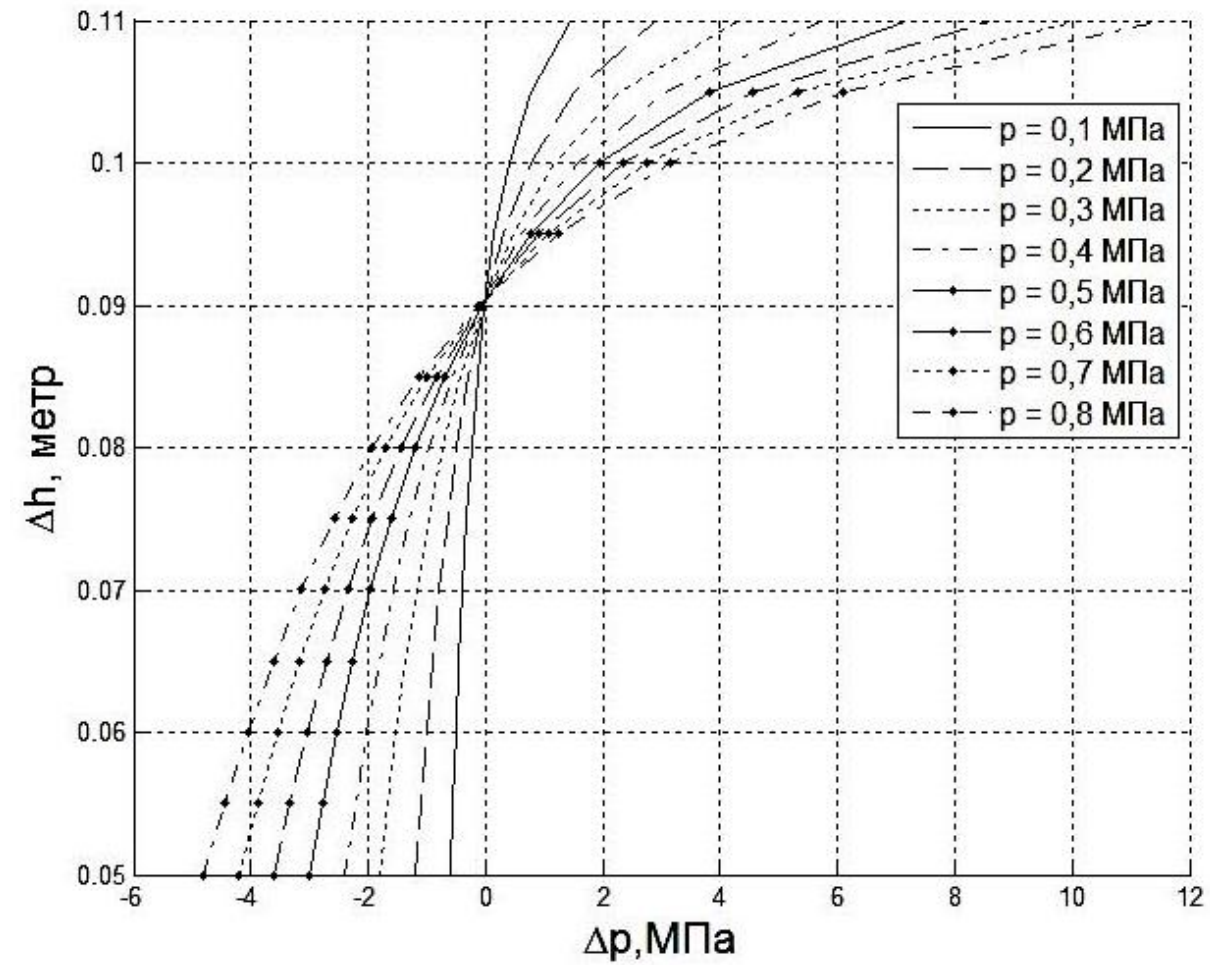

Fig. 6. Coefficient of correlation between height increment and pressure increment

$$
\Delta p=\frac{p\left(\begin{array}{c}
2 \pi \sqrt{\left(\frac{\Delta h}{2}\right)^{2}+r^{2}}\left(\operatorname{arctg}\left(\frac{h}{2 r}\right)\right) \times \\
\times\left(\sqrt{\left(\frac{\Delta h}{2}\right)^{2}+r^{2}} \cos \left(\operatorname{arctg}\left(\frac{h}{2 r}\right)\right)-r\right)- \\
-2 \pi \sqrt{\left(\frac{\Delta h}{2}\right)^{2}+r^{2}}\left(2 \sqrt{\left(\frac{h}{2}\right)^{2}+r^{2}}+\sqrt{\left(\frac{\Delta h}{2}\right)^{2}+r^{2}}\right) \sin \left(\operatorname{arctg}\left(\frac{h}{2 r}\right)\right)
\end{array}\right)}{\left(\begin{array}{c}
\pi r^{2}+2 \pi\left(\sqrt{\left(\frac{h}{2}\right)^{2}+r^{2}}+\sqrt{\left(\frac{\Delta h}{2}\right)^{2}+r^{2}}\right)\left(\operatorname{arctg}\left(\frac{h}{2 r}\right)\right) \times \\
\times\left(r-\left(\sqrt{\left(\frac{h}{2}\right)^{2}+r^{2}}+\sqrt{\left(\frac{\Delta h}{2}\right)^{2}+r^{2}}\right) \cos \left(\operatorname{arctg}\left(\frac{h}{2 r}\right)\right)\right)+ \\
+2 \pi\left(\sqrt{\left(\frac{h}{2}\right)^{2}+r^{2}}+\sqrt{\left(\frac{\Delta h}{2}\right)^{2}+r^{2}}\right)^{2} \sin \left(\operatorname{arctg}\left(\frac{h}{2 r}\right)\right)
\end{array}\right)}
$$

\section{Modelling results}

Modelling is made in Matlab Simulink package software at sinusoidal input. Nonlinear characteristics needed for calculations are dynamically linearized. It means, that parameters of transfer function shown in differential equation form (4) recalculating in every point during two-way bellow actuator workout. It can be achieved because every coefficient and correlation depends on current height. It improves accuracy of this model. Earlier linearization parameters were constant and were made in one point (in neutral position).

At Fig. 7 is shown the reaction on sinusoidal input signal with frequency of $1.6 \mathrm{~Hz}$ and range $0.005 \mathrm{~m}$. This operation mode can be used at vibration testing.

As it is shown in this paper (pp. 3.1-3.3) characteristics of bellow actuator are nonlinear. The same time modelling results presented at Fig. 7 indicate that developed mathematical model of two-way bellow actuator possess required accuracy with amplitude error of $1 \%$, phase error $-3 \%$. It is achieved with a help of consideration of transfer function parameters variation during its performance. Therefore for control of presented two-way bellow actuator (Fig. 2) there is no need to resort to complicated control methods. 


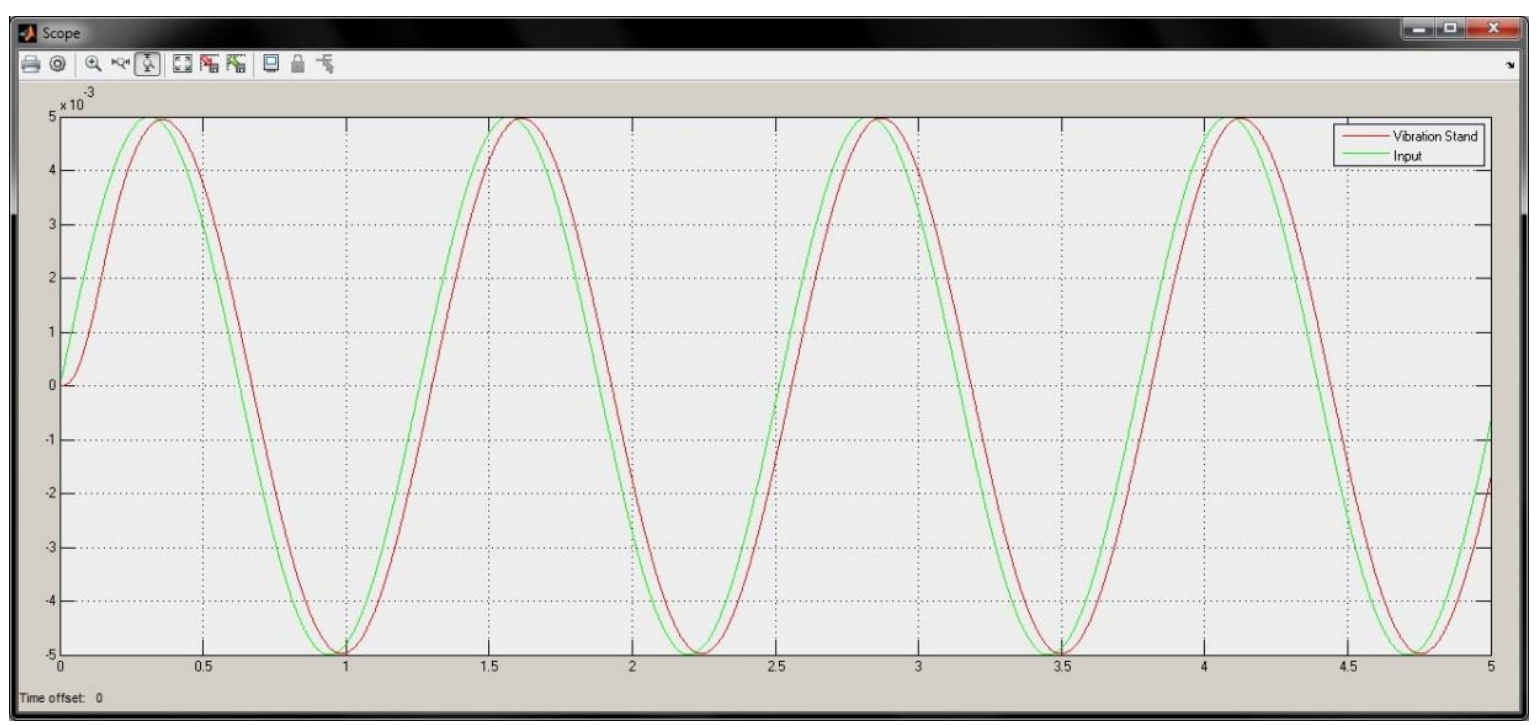

Fig. 7. Reaction on sinusoidal input signal

\section{Conclusion}

In this paper is shown position modelling of a two-way bellow actuator. The main idea of making this modelling was consideration of transfer function parameters variation during performance of two-way bellow actuator to decrease model error. Development of model includes:

- Development of simulation model

- Evaluation of main nonlinear characteristics of two-way bellow actuator

- Verifying results with a help of modelling

The emphasis was made on development of accurate easy-to-calculate mathematical model of two-way bellow actuator. Such model together with reliable models of electro-pneumatic throttle spool-type valves allow to receive more accurate pneumatic drive model.

The logical next step would be verification of received results by experimental data.

\section{References}

[1] G. Adolf and coll., Development of a robotic device to improve chronic ankle instability through controlled perturbation, Bioengineering Conference (NEBEC), Boston, MA, 2014, pp. 1-2.

[2] B. Wang, Aw C. Aw, M. Biglari-Abhari, A. McDavid, Modelling of Pneumatic Air Muscles for Direct Rotary Actuation of Hand Rehabilitation Glove, Social Robotics, 2014, pp. 360-369.

[3] J. Sarosia, I. Birob, J. Nemethc, L. Cveticanind, Dynamic modelling of a pneumatic muscle actuator with twodirection motion, Mechanism and Machine Theory, 2015, pp. 25-34.

[4] J. Pitel, R. Neydorf, J. Borzikova, Arm position simulation of PAM based actuator, Annals of DAAAM, Vienna, Austria, 2011, pp. 0145-0146.

[5] J. Pitel, Modelling of the PAM Based Antagonistic Actuator, Cybernetic Letters, 2008.

[6] P. Chernus, V. Sharovatov, Dynamic Mathematical Model of Two-Way Bellow Actuator, Procedia Engineering, 2015, pp. 1040-1045.

[7] V. Sharovatov, P. Chernus, Mathematical Model of a Strength Part of a Push Type Single-Acting Rodless Pneumatic Cylinder, Mechatronics, Automation, Control, №9, 2014, pp. 30-36.

[8] Catalogue Avaliable from: http://www.festo.com/cat/ru_ru/data/doc_engb/PDF/EN/EB_EN.PDF.

[9] Pav. Chernus, V. Sharovatov, Development of simplified mathematical models of force part of push-type rodless pneumatic cylinder, Materials of All-Russian Symposium Mechanics and Control Processes, Miass, Russia, 2012, pp. 69-80. 